\title{
APOع2 and education in cognitively normal older subjects with high levels of AD pathology at autopsy: findings from the Nun Study
}

\author{
Diego Iacono ${ }^{1,2,3,4}$, Peter Zandi ${ }^{5}$, Myron Gross ${ }^{6}$, William R. Markesbery ${ }^{7,8,9}$, Olga \\ Pletnikova $^{1}$, Gay Rudow ${ }^{1}$ and Juan C. Troncoso ${ }^{1,10}$ \\ ${ }^{1}$ Neuropathology Division, Department of Pathology, Johns Hopkins University, Baltimore, MD, USA \\ ${ }^{2}$ Neuropathology Research, Biomedical Research Institute of New Jersey, Cedar Knolls, NJ, USA \\ ${ }^{3}$ Atlantic Neuroscience Institute, Overlook Medical Center, Summit, NJ, USA \\ ${ }^{4}$ Department of Neurology, Icahn School of Medicine at Mount Sinai, New York, NY, USA \\ ${ }^{5}$ Department of Mental Health, Johns Hopkins University, Baltimore, MD, USA \\ ${ }^{6}$ Department of Laboratory Medicine and Pathology, University of Minnesota, Minneapolis, MN, USA \\ 7 Department of Pathology, Sanders-Brown Center on Aging, University of Kentucky, Lexington, KY, USA \\ ${ }^{8}$ Department of Neurology, Sanders-Brown Center on Aging, University of Kentucky, Lexington, KY, USA \\ ${ }^{9}$ Alzheimer's Disease Center, Sanders-Brown Center on Aging, University of Kentucky, Lexington, KY, USA \\ 10 Department of Neurology, Johns Hopkins University, Baltimore, MD, USA \\ Correspondence to: Diego lacono, email: diego.iacono@atlantichealth.org \\ Keywords: Gerotarget, AD pathology, APOع2, higher education and language skills, neuronal hypertrophy, preserved cognition \\ Received: March 11, 2015 \\ Accepted: April 30, 2015 \\ Published: May 12, 2015
}

This is an open-access article distributed under the terms of the Creative Commons Attribution License, which permits unrestricted use, distribution, and reproduction in any medium, provided the original author and source are credited.

\section{ABSTRACT}

Asymptomatic Alzheimer's disease (ASYMAD) subjects are individuals characterized by preserved cognition before death despite substantial AD pathology at autopsy. ASYMAD subjects show comparable levels of AD pathology, i.e. $\beta$-amyloid neuritic plaques (A $\beta-N P$ ) and tau-neurofibrillary tangles (NFT), to those observed in mild cognitive impairment (MCI) and some definite AD cases. Previous clinicopathologic studies on ASYMAD subjects have shown specific phenomena of hypertrophy in the cell bodies, nuclei, and nucleoli of hippocampal pyramidal neurons and other cerebral areas. Since it is well established that the allele APO\&4 is a major genetic risk factor for AD, we examined whether specific alleles of APOE could be associated with the different clinical outcomes between ASYMAD and MCI subjects despite equivalent AD pathology. A total of 523 brains from the Nun Study were screened for this investigation. The results showed higher APOع2 frequency $(p<0.001)$ in ASYMAD (19.2\%) vs. MCI $(0 \%)$ and vs. AD $(4.7 \%)$. Furthermore, higher education in ASYMAD vs. MCI and AD $(p<0.05)$ was found. These novel autopsy-verified findings support the hypothesis of the beneficial effect of APOE2 and education, both which seem to act as contributing factors in delaying or forestalling the clinical manifestations of AD despite consistent levels of AD pathology.

\section{INTRODUCTION}

Many decades of clinicopathologic investigations on sporadic Alzheimer's disease (AD) have enormously contributed to the definition of the main pathologic lesions associated with $\mathrm{AD}$, i.e. $\beta$-amyloid neuritic plaques $(\mathrm{A} \beta$ NP) and tau-neurofibrillary tangles (tau-NFT), and to a better understanding of the possible relationships between cognitive deficits and $\mathrm{AD}$ lesions $[1,2]$. However, the exact mechanisms leading to those pathologic hallmarks of $\mathrm{AD}(\mathrm{A} \beta$-NP, tau-NFT) and how they determine neuronal degeneration in specific areas of human brain (i.e., entorhinal cortex, hippocampus) yet remain to be yet completely clarified [3-5]. The hypothesis that $\mathrm{A} \beta$ - 
$\mathrm{NP}$, tau-NFT, as well as $\mathrm{A} \beta$ or tau oligomers, are the only responsible factors for the cognitive declining in $\mathrm{AD}$ has not been satisfactorily confirmed by a series of neuropathologic, neuroimaging, and biochemical studies attempting to establish linear correlations between $\mathrm{AD}$ pathology and cognitive decline [6-12]. One of the most convincing evidences of the absence of linearity between cognitive deficits and $\mathrm{AD}$ pathology is the frequent observation, at autopsy, of a considerable number of older individuals with high burdens of $\mathrm{A} \beta$-NP and tau-NFT with preserved cognition as assessed shortly prior to death (i.e. $<1$ year). These older individuals with preserved cognition and consistent amounts of AD pathology at autopsy have been termed asymptomatic AD (ASYMAD) subjects. ASYMAD subjects not only have comparable levels of AD pathology to those found in mild cognitive impairment (MCI) subjects and some definite AD patients but also have an identical cerebral localization $[13,15]$. Other investigators referred to ASYMAD under different appellations, such as "high pathology controls" [16] or "preclinical AD" [17]. Those investigators essentially referred to the same concept: there are older individuals cognitively silent for $\mathrm{AD}$ even with consistent levels of $\mathrm{AD}$ pathology at autopsy. This clinicopathologic dissociation has also been described employing "in vivo" functional neuroimaging studies [18-22].

The reason to term older individuals cognitively preserved but positive for AD pathology at autopsy using the acronym ASYMAD is because it is virtually impossible to know "a priori" whether these subjects would have remained cognitively preserved or eventually would have progressed to MCI or AD had they lived longer. The term ASYMAD then has the advantage to not imply necessarily a forthcoming or future cognitive decline [23]. In addition, the ASYMAD term can be easily applied to other fields of $\mathrm{AD}$ and aging research, such as functional neuroimaging [24].

It is significant to recall here that a clinicopathologic dissociation between AD pathology and cognition was already recognized a few decades ago [25-31] without receiving, unfortunately, any major scientific attention. Recently however, the discrepancy between cognitive aspects and AD pathology has been implicitly accepted by newer AD pathologic criteria $[32,33]$. These criteria do not require a diagnosis of dementia to stage the AD pathology at autopsy. They "simply" propose a probabilistic scoring system for the AD neuropathologic changes, which uses previously established systems of $\mathrm{A} \beta$-NP and NFT staging without taking into account any clinical or dementia history of the subject that received the autopsy.

In previous studies [34-37], a marked neuronal hypertrophy in different cerebral regions of ASYMAD subjects vs. age-matched controls (C), MCI and $\mathrm{AD}$ subjects was measured. These cellular changes have been hypothesized to be possible neuronal reactions or part of compensatory mechanisms facing the accumulation of $\mathrm{AD}$ pathology, which would allow normal cognitive functioning despite abundant $\mathrm{AD}$ pathology. In agreement with this compensatory hypothesis, phenomena of neuroplasticity have been described by functional neuroimaging studies enrolling $\mathrm{MCI}$ and early-AD patients and also, importantly, high-risk subjects for AD, that is subjects without cognitive signs of the disease [3741].

This new clinicopathologic investigation aimed to go beyond the morphometric characterizations [35, 36] and quantitative measurements of AD pathology in ASYMAD vs. Controls, MCI, and definite AD [42] and possibly describe other contributing factors which could underlie the cognitive resilience of ASYMAD subjects despite AD pathology.

There are very few large epidemiological studies that include analyses of normal aging and $\mathrm{AD}$, and an autopsy program. Among those rarer epidemiological studies, the Nun Study has been a historical one [43]. Rendering use of the wealth of longitudinal clinical information and rigorous pathological observations available from the Nun Study [43, 44], we aimed to analyze the allelic frequencies of APOE gene (APOE) and the attained education levels of the entire available sample of this unique autopsy-cohort. APO 2 , one of the three alleles of APOE [45], and higher education levels have been shown to have protective capacities against AD [46, 47]. The principal aim and novelty of this investigation was to verify if APO\&2 frequency and education levels were indeed significantly higher in ASYMAD subjects from the Nun Study. An adjunctive potential novelty of this study consisted in the opportunity to associate those possible findings on the protective effects of APO 2 and higher education taking also into account previously described phenomena of neuronal hypertrophy in ASYMAD subjects from the same study [37], as well as their association to higher language skills acquired early in life. Higher earlyacquired language skills have been demonstrated to reduce the risk of dementia [48-49].

\section{RESULTS}

Demographic, educational, cognitive, neuropathologic, and APOE allele distribution data across groups are summarized in Table 1. Statistical analyses did not show differences for the mean age at death, age at last cognitive assessment, and Cog-Death interval across all groups. BW was not different among ASYMAD, MCI, and $\mathrm{C}$, although the mean $\mathrm{BW}$ was lower in $\mathrm{AD}$ compared with all other groups.

ASYMAD and C did not differ for the last MMSE and ADLs mean scores. By contrast, AD showed significantly lower MMSE and ADLs mean scores compared to all other groups.

$\mathrm{A} \beta$-NP CERAD scores showed no statistical 
Table 1: Demographic, educational, cognitive, neuropathologic, and APOE frequencies of 155 subjects with autopsyconfirmed diagnosis and interval Cog-Death $\leq 1.0$ year

\begin{tabular}{|c|c|c|c|c|}
\hline & $\begin{array}{l}\text { Controls } \\
(n=11 ; 7.1 \%)\end{array}$ & $\begin{array}{l}\text { ASYMAD } \\
(n=13 ; 8.3 \%)\end{array}$ & \begin{tabular}{|l|} 
MCI \\
$(n=15 ; 9.6 \%)$
\end{tabular} & $\begin{array}{l}\mathrm{AD} \\
(n=116 ; 74.8 \%)\end{array}$ \\
\hline Interval cog-death (years) & $0.5 \pm 0.2$ & 0.50 .2 & $0.5 \pm 0.2$ & 0.40 .2 \\
\hline Age at death (years) & $86.9 \pm 5.7$ & $89.5 \pm 2.1$ & $89.4 \pm 4.5$ & $92.2 \pm 4.6$ \\
\hline Age at last cog (years)* & $86.4 \pm 5.8$ & $89.0 \pm 2.3$ & $88.8 \pm 4.5$ & $91.7 \pm 4.6$ \\
\hline Last MMSE* & $27.8 \pm 1.3$ & $28.3 \pm 1.1$ & $26.0 \pm 1.4$ & $8.0 \pm 8.1$ \\
\hline ADLs* & $5.0 \pm 0.0$ & $5.0 \pm 0.0$ & $4.7 \pm 0.4$ & $0.9 \pm 1.5$ \\
\hline $\begin{array}{l}\text { Education (\%) } \\
\text { Grade school only } \\
\text { High school diploma } \\
\text { Bachelor degree } \\
\text { Masters or higher }\end{array}$ & $\begin{array}{c}0.0 \\
0.0 \\
36.6 \\
63.4\end{array}$ & $\begin{array}{c}7.6 \\
0.0 \\
30.7 \\
61.5\end{array}$ & $\begin{array}{l}6.6 \\
0.0 \\
60.0 \\
33.3\end{array}$ & $\begin{array}{l}16.3 \\
7.7 \\
46.5 \\
29.3\end{array}$ \\
\hline Brain weight (grams) & $1182.2 \pm 259.3$ & $1144.5 \pm 80.5$ & $1170.3 \pm 110.9$ & $1083.9 \pm 117.1$ \\
\hline $\begin{array}{c}\text { CERAD score (\%)* } \\
\text { 0 } \\
\text { B } \\
\text { C }\end{array}$ & $\begin{array}{c}100 \\
0 \\
0\end{array}$ & $\begin{array}{c}0.0 \\
76.9 \\
23.0\end{array}$ & $\begin{array}{c}0.0 \\
73.3 \\
26.6\end{array}$ & $\begin{array}{c}0.0 \\
41.3 \\
58.6\end{array}$ \\
\hline $\begin{array}{c}\text { NFT Braak score }(\%) \\
\text { 0 } \\
\text { I } \\
\text { II } \\
\text { III } \\
\text { IV } \\
\text { V } \\
\text { VI }\end{array}$ & $\begin{array}{c}18.1 \\
27.2 \\
54.5 \\
0.0 \\
0.0 \\
0.0 \\
0.0\end{array}$ & $\begin{array}{c}0.0 \\
15.3 \\
69.2 \\
15.3 \\
0.0 \\
0.0 \\
0.0\end{array}$ & $\begin{array}{c}0.0 \\
6.6 \\
33.3 \\
6.6 \\
20.0 \\
33.3 \\
0.0\end{array}$ & $\begin{array}{c}0.8 \\
3.4 \\
12.0 \\
12.0 \\
11.2 \\
22.4 \\
37.9\end{array}$ \\
\hline$\varepsilon 2$ allele frequency $(\%)^{*}$ & 13.6 & 19.2 & 0 & 4.7 \\
\hline \&3 allele frequency (\%) & 86.3 & 76.9 & 70.0 & 75.8 \\
\hline 84 allele frequency $(\%)^{*}$ & 0 & 3.8 & 30.0 & 19.4 \\
\hline
\end{tabular}

*Differences across groups were significant at $p<0.01$. Controls: age-matched controls; ASYMAD: asymptomatic AD subjects; MCI: mild cognitive impairment subjects; AD: Alzheimer's disease patients. The interval Cog-Death (the interval of time between the last cognitive assessment and death), age at death, age at last cognitive exam, last MMSE, ADLs, and brain weight are expressed as mean $\pm \mathrm{SD}$. The first row of the table shows the sample size ( $\mathrm{n}$ and percentages) of each group respect to the total sample size $(n=155)$ of the study. The table shows also the single APOE allele $(\varepsilon 2, \varepsilon 3$, and $\varepsilon 4)$ frequencies for each group.

difference between ASYMAD and MCI, whereas differences were found between ASYMAD and AD ( $p$ $<0.05)$; and between MCI and AD $(p<0.05)$. BraakNFT scores were different across comparisons when all stages $(0-\mathrm{VI})$ were considered: ASYMAD vs AD $(p<$ $0.001)$, MCI vs $\mathrm{AD}(p<0.01)$, and ASYMAD vs MCI $(p<0.05)$. However, when the analysis of Braak staging was performed including only the first five stages (0-IV), no differences were observed between ASYMAD vs. MCI and even between MCI and AD.

Higher APO\&2 frequency was found in ASYMAD $(19.7 \%)$ compared to $\mathrm{MCI}(0 \%, p<0.01)$ and $\mathrm{AD}(4.7 \%$, $p<0.01)$. No different APO 2 frequency was detected between ASYMAD and C (13.6\%). While no differences were observed in APO\&3 frequency across all groups, lower APO 84 frequency was observed in ASYMAD (3.8\%) compared to MCI $(30.0 \%, p<0.01)$ and $\mathrm{AD}$ $(19.4 \%, p<0.01)$. Importantly, no different APO $\varepsilon 4$ frequency was found between ASYMAD and C (0\%). All comparisons for APOE allelic frequencies are shown in Figure 1.
Moreover, APO\&2 frequency was significantly higher $(p=0.004)$ in PCG $(\mathrm{C}+\mathrm{ASYMAD}, \varepsilon 2=16.6 \%)$ compared to ICG $(\mathrm{MCI}+\mathrm{AD}, \varepsilon 2=4.2 \%)$ (Figure 2$)$. By contrast, whereas $\mathrm{APO} \varepsilon 3$ frequency did not show any difference between these two groups, APO 44 frequency was significantly higher $(p=0.001)$ in ICG $(\varepsilon 4=20.6 \%)$ compared to PCG $(\varepsilon 4=2.0 \%)$.

The analyses show significant differences on education levels between PCG compared to ICG $(p=0.02)$ group. Correlation analyses (Spearman's test) between APO 2 and the highest level of attained education (master or higher), however, did not show significant correlations across all groups, or any other possible correlation between groups comparison.

\section{DISCUSSION}

The most important findings of this clinicopathologic study are: a) higher APOع2 frequency and b) higher educational levels in ASYMAD vs. MCI and AD. These findings suggest a beneficial effect of 
APOع 2 and education on later cognition even in presence of $\mathrm{AD}$ pathology burdens that are equivalent to those found in the MCI and some definite AD cases. Previous epidemiological studies have reported a protective role of APOE2 [46] and higher education [60] against AD, but only few have been confirmed by autopsy findings [61]. To the best of our knowledge, this is the first clinicopathologic study showing a significant association between higher APOe2 frequency and higher education in a cohort of autopsy-confirmed ASYMAD vs. MCI, and AD subjects. Moreover, from the same autopsy-cohort, a previously examined group of ASYMAD subjects was associated with specific cellular morphometric changes, such as neuronal hypertrophy in CA1 of hippocampus and higher language skills acquired in early life [37]. Unfortunately, the limited availability of hippocampi from all autopsy cases of this study did not allow to verify those significant correlations among CA1-neuronal hypertrophy, APOع2, and education/language across the entire autopsy-cohort. However, this investigation seems to offer important seminal perspectives on the possible interaction among AD pathology, APOE genotypes, education/language, and mechanisms of neuroplasticity. These intriguing cognition-pathology-genotype-neuroplasticity correlations remain to be verified by future larger autopsy-studies. However, a recent non-autopsy study confirmed our previous findings [37] on the beneficial effect of APOE2 on lifetime experiences enhancing cognition, which was better indicated by measuring specific linguistic skills (i.e., vocabulary and reading ability) [62].

In terms of pathogenic sequence, our findings suggest that the possible beneficial effects of APOE2 and higher education lie downstream to both $\mathrm{A} \beta$ and tau depositions, and are possibly linked to multiple biological mechanisms [63-64]. A recent larger neuropathologic study [65], which analyzed a larger amount of pathologic and clinical data from the National Alzheimer's Coordinating Center (NACC) dataset, had the chance to stratify a higher number of subjects based on their levels of AD pathology and clinical manifestation. Their findings are in line
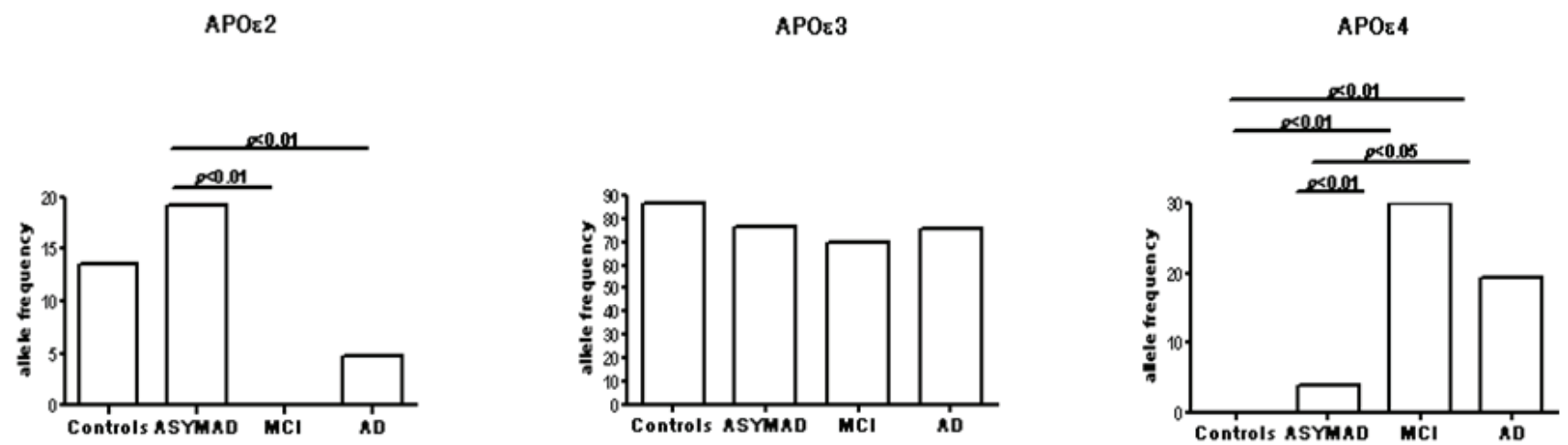

Figure 1: The figure shows histograms for the frequency distribution of APO $\varepsilon 2, \varepsilon 3$, and $\varepsilon 4$ alleles in the four different groups examined in the study.

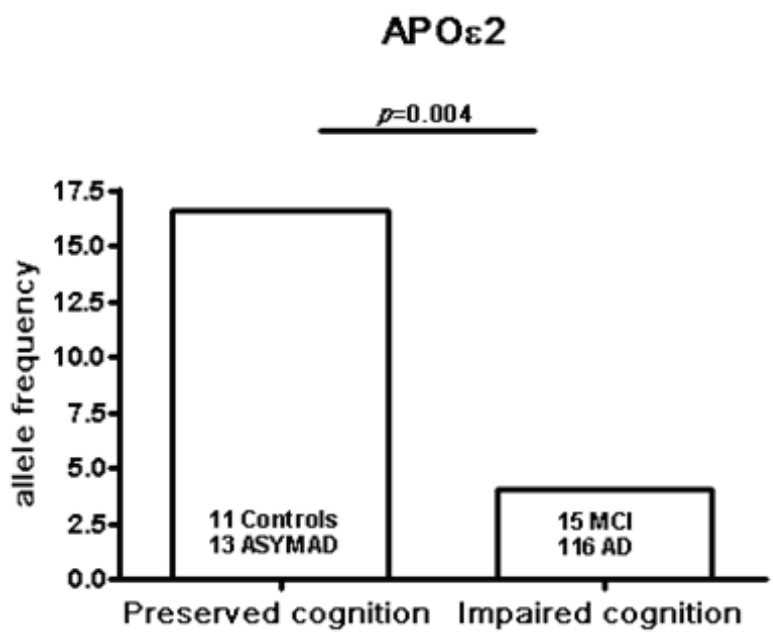

A
Master's degree or higher

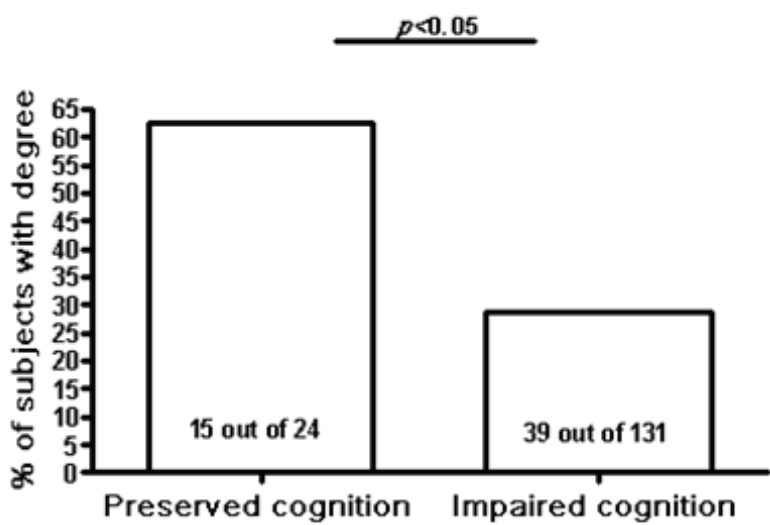

B

Figure 2: The figure shows the histograms for APO 2 frequencies and educational levels in two different groups: 1) preserved cognition group (PCG): controls+ASYMAD subjects; and 2) impaired cognition group (ICG): MCI+AD patients. The p-values are the statistical significance values after exact Fisher's test. 
with ours regarding the protective effect of APOE2 even after adjustments for influencing factors such as the age of onset, duration of symptoms, and other demographic variables. Although the nature of the population analyzed in this larger study [65] is different from ours, the findings are impressively similar. Moreover, our findings not only seem to confirm the results from a larger study [65] but also extend them. In fact, the novelty of our investigation consists not only in supporting that ASYMAD are subjects associated with higher APO 2 frequency and education but also with specific morphometric-neuronal changes [37] and cognitive skills, such as higher early-acquired language skills [37, 48, 49].

Moreover, experimental studies indicate that APO 2 has a protective role in both the peripheral and central nervous system [66, 67]. Furthermore, data describe APOع2's enhancing capacity to increase neuritic growth in contrast to APO 84 which demonstrates a detrimental effect on it [68, 69].

Remarkably, APO\&3 frequency was not different across all groups in our investigation. This suggests that it is actually the interplay between APO 22 and APO 44 to weigh heavily on the risk of developing MCI and AD, or remaining cognitively unscathed. Importantly, only the presence of APO\&2 is insufficient to avoid the AD pathology deposition, as demonstrated by the conspicuous amount of it in ASYMAD subjects. APO 2 , rather, seems to have beneficial properties in reducing the consequences of AD pathology accumulation or even in reducing it [70].

APOE distribution in the Nun Study is similar to that of Caucasian populations [71]. However, it is important to emphasize that APO\&2 frequency in this Nun Study autopsy-cohort was curiously higher (19.2\%) than that observed in Caucasians (2-8\%). This could be related to the possible role of APOE2 on survival and longevity [72-74]. The involvement of APO\&4 as risk factor for cardiovascular diseases [75] and enhanced innate immune response [76], could exclude these subjects from normal aging and AD longitudinal studies.

How common is ASYMAD? In our series, out of 24 cognitively preserved subjects (C+ASYMAD) older than 85 years (mean age $=88.2 \pm 3.9$ ), 54.0\% showed severe levels of AD pathology but unimpaired cognition (ASYMAD). A previous large autopsy-cohort study [77] showed that $30 \%$ of subjects diagnosed with probable $\mathrm{AD}$ have insufficient $\mathrm{AD}$ neuropathological changes at autopsy to satisfy a diagnosis of definite AD. While those data showed insufficiency of AD pathology to explain the dementia in a high number of subjects, we substantiate that even with equivalent amounts of AD pathology, other factors such as APOع2, education, and early acquired language/cognitive skills [33] are indeed associated with a decreased risk, delay, or even avoidance of dementia.

It is not possible to transfer our findings to the general population without caveats. We cannot exclude that the higher educational levels of the Nun Study participants contributed to a higher "cognitive reserve" [78]. In the Nun Study though, this issue could be less of a challenge since all sisters shared the lifestyle and comparable medical care. Other caveats could be the exclusion of those factors that can also impair the cognition: cerebro-vascular hypoxic phenomena, metabolic disorders, diabetes, hyperlipidemia, untreated hypertension, hypercaloric diet, alcohol abuse, or environmental and lifestyle stressors. It is neither possible to exclude that two brains can have similar numbers of $\mathrm{A} \beta$-NP and NFT, but one brain has a higher concentration of toxic and specific soluble $\mathrm{A} \beta$ or tau oligomers than the other [12], and its risk of functional impairment is therefore enhanced. Genetic factors different from APOE and non-genetic factors different from education could also mutually interact. Complex gene-environment interactions, in fact, seem to determine an increased or decreased risk of dementia later in life. Recent studies on twins describe, for example, that even identical twins can differ in their onset of dementia and have different amounts of AD pathology at autopsy [79].

\section{MATERIALS AND METHODS}

Subjects were identified by querying the database of the Nun Study, which includes clinical and cognitive data, educational information, neuropathologic evaluations with definite diagnoses, and APOE genotypes. Participants in the Nun Study are Catholic sisters belonging to the School Sisters of Notre Dame congregation living in various communities in the Midwestern, eastern, and southern regions of the US [43]. At the time of the enrollment period all sisters born before 1917 were asked to participate in the study. Of 1027 eligible sisters (aged 75 years or older), $678(66.0 \%)$ agreed to participate in the study. All sisters participating in the study signed an informed written consent form and agreed to annual physical and cognitive assessments and review of their medical records. They also consented to donate their brains for research after death. The Nun Study autopsy procedures were approved by the University of Kentucky's Institutional Review Board. In 2010, the Nun Study moved back to its original Institution, the University Of Minnesota.

In the present investigation only the participants that underwent autopsy were considered. The total sample size of the cohort with brain autopsy available was 523, that is, the $77.1 \%$ of the entire eligible cohort. The methods used to assess the cognitive status have been described in previous publications [50]. Briefly, the cognitive test battery included measures compiled by the Consortium to Establish a Registry for Alzheimer's disease (CERAD) [51], which assesses memory, language, visuo-spatial ability, concentration, and orientation. In the Nun Study, this neuropsychological battery was administered by two trained gerontologists. Five of the tests from the CERAD battery were used to define preserved cognitive function: 
Mini-Mental State Exam (MMSE), Delayed Word Recall, Boston Naming, Verbal Fluency, and Constructional Praxis. The standard cut point of 24 or greater was used to identify intact scores for the MMSE. For the other four tests, cut points that were close to, but did not exceed the 5 th percentile for the normative data described by the CERAD group [52], were identified to classify individual test scores as intact or impaired. The cut points for intact scores were as follows: $\geq 13$ for Boston Naming, $\geq 11$ for Verbal Fluency, $\geq 4$ for Delayed Word Recall, and $\geq 8$ for Constructional Praxis. Participants judged to be cognitively intact in the present analyses had intact scores on all five tests. Individuals who were classified as demented in the study had each of the following conditions: (a) impairment in memory and in at least one other area of cognition, (b) impairment in social or daily function (i.e., inability to use a phone, handle money, or dress oneself), and (c) decline in function from a previous level (observed during our study for the incident dementia cases, or inferred for those dementia cases present at the first exam). From the above described battery, the following classification system was established to define a subject cognitively as:

Intact (Preserved) Cognition: intact scores on all cognitive tests and activities of daily living (ADL). This category defined the cognition level of both age-matched controls (C) and ASYMAD subjects.

Mildly Impaired Cognition (with memory impairment): intact on MMSE and ADL, but impaired on the Delayed Word Recall and one or more of the other three cognitive tests. This category is equivalent to mild cognitive impairment (MCI) subjects based on Mayo Clinic and AA-NIA MCI criteria [53, 54].

Demented: met clinical criteria for dementia as described above.

\section{Neuropathologic material and methods}

The Nun Study had neuropathological data on a total of 523 autopsy brains. These brains were removed and examined macroscopically after fixation in $10 \%$ buffered formaldehyde for at least 2 weeks. Tissues blocks were dissected from middle frontal gyrus, superior and middle temporal gyri, inferior parietal lobule, occipital cortex (area 17-18), entorhinal cortex, hippocampus, amygdala, thalamus, basal ganglia and cerebellum. Tissue blocks were processed and embedded in paraffin, cut at $10 \mu \mathrm{m}$, and stained with hematoxylin-eosin (H\&E) and Hiranosilver method. The severity of $\mathrm{A} \beta$-NP was assigned by semi-quantitative and age-adjusted scores $(0, \mathrm{~A}, \mathrm{~B}$, or C) according to CERAD pathologic criteria [55], and NFT stages were scored (0-VI) according to Braak-NFT system [56]. Out of the total of 523 autopsies, subjects were selected only if the following criteria were satisfied:

1) Subjects with complete physical, neurologic, and cognitive assessment in an interval prior to death (Cog-
Death interval) of $\leq 1.0$ year.

2) Neuropathologic assessments including CERAD pathologic diagnostic and Braak-NFT scores

3) Availability of APOE genotype.

Subjects were excluded if:

1) Met the criteria for mixed dementia. This exclusion criteria was particularly important to minimize the influence of cerebro-vascular pathologies on the cognitive deficits.

2) Met the criteria for dementia with Lewy bodies, Parkinson's disease with dementia, Pick's disease, Creutzfeldt-Jacob disease.

3) Showed hippocampal sclerosis, tauopathies, or primary or secondary brain tumors.

Based on the clinical, cognitive, and neuropathologic assessment and above described inclusion/exclusion criteria, we identified a total of 155 subjects suitable for this study. These subjects were assigned to four study groups:

1) Age-matched controls (C): subjects with intact cognition and no significant AD pathology at autopsy $(\mathrm{CERAD}=0$; Braak 0-II) $(n=11)$;

2) Asymptomatic AD (ASYMAD): subjects with intact cognition and AD pathology at autopsy (CERAD: B-C; Braak 0-VI) $(n=13)$;

3) Mild cognitive impairment (MCI): subjects with MCI diagnosis and AD pathology at autopsy (CERAD: B-C; Braak: 0-VI) $(n=15)$;

4) Alzheimer's disease (AD), patients with clinical dementia and diagnosis of definite $\mathrm{AD}$ at autopsy (CERAD: B-C; Braak: 0-VI) $(n=116)$.

We decided not to classify these cases with neither NIA-Reagan criteria [57] nor AA-NIA criteria [58]. The reasons for this were:

1) NIA-Reagan criteria apply to autopsy cases with previously ascertained dementia, then per se, not applicable to C or ASYMAD;

2) AA-NIA pathologic criteria do not take into account the diagnosis of dementia to stage neuropathologic AD changes, so excluding an important aim of our study: analyzing the presence or absence of cognitive impairment as related to AD pathology, APOE genotype and educational levels.

Moreover, NIA-Reagan and AA-NIA criteria are probabilistic systems of classification relying on $\mathrm{A} \beta$-NP and NFT scores with the assumption that a cumulative pathogenetic contribution to $\mathrm{AD}$ pathogenesis is actually originating from both types of pathology. This assumption has not been demonstrated yet. Although NIA-Reagan and AA-NIA criteria have an undoubted practical utility in a clinical setting, in this investigation we preferred to consider CERAD and Braak scores separately. This choice was also useful to verify possible distinct cognitivepathologic-genotype correlations as subjacent to different pathogenetic mechanisms, such as $\mathrm{A} \beta$-NP or NFT formation. 


\section{APOE genotyping}

APOE genotype analyses on all study subjects have been conducted on DNA isolated from buccal swabs (archival) or from brain tissues as previously described [59].

\section{Statistical analyses}

ANOVA was used to compare continuous variables (i.e. mean age at death, mean age at last cognitive examination before death, mean score of the last MMSE, mean scores of ADLs, and mean brain weight [BW]) across all groups; while Fisher's exact test was used to compare categorical variables (i.e. CERAD pathological scores, Braak-NFT staging, and educational levels attained).

For APOE allelic frequency analyses, we used Fisher's exact test for a 3-by-4 contingency table comparing the frequencies of all three APOE allele across all groups. Then, we carried out analyses to examine the hypothesis that APOE2 was enriched in ASYMAD by conducting additional Fisher's exact test to compare the frequencies of APOE2 vs. all other alleles in ASYMAD vs $\mathrm{MCI}, \mathrm{AD}$, and $\mathrm{C}$, separately.

In addition, an exact Fisher's test was performed to compare the APOE allelic frequencies in two larger combined groups: 1) subjects with cognitive deficits (MCI+AD) (impaired cognition group, ICG); and 2) subjects without cognitive deficits (C+ASYMAD) (preserved cognition group, PCG). This analysis was performed to investigate possible effects of APO 2 exclusively based on the documented cognitive assessment shortly before death. Separate analyses using an exact Fisher's test were performed to compare ICG and PCG on the highest educational level attained. Finally Spearman's test for nonparametric data (APO\&2 frequencies) and highest level of education attained (master or higher) across all groups, expressed as percentages, was also performed to test if significant correlation between APO $\varepsilon 2$ and higher education was possibly present.

\section{ACKNOWLEDGMENTS}

We are greatly indebted to all the sisters enrolled in the Nun Study and the School Sisters of Notre Dame congregation, as well as to Dr. David Snowdon, first director and founder of the study.

"This work is especially in memory of Dr. William R. Markesbery ("Bill"): his impressive contribution to the Nun Study success, his vast neuropathologic knowledge, and his dedication and passion for teaching will never be forgotten.

\section{FUNDING}

This work was supported by the Johns Hopkins University Alzheimer's Disease Research Center (NIH grant AG05146), the Nun Study (NIA grants: R01AG09862, K04AG00553, University of Kentucky Alzheimer's Disease Center (NIH grant AG028383).

\section{CONFLICTS OF INTEREST}

Authors declare no conflicts of interests.

\section{REFERENCES}

1. Nelson PT, Alafuzoff I, Bigio EH, Bouras C, Braak H, Cairns NJ, Castellani RJ, Crain BJ, Davies P, Del Tredici K, Duyckaerts C, Frosch MP, Haroutunian V, Hof PR, Hulette CM, Hyman BT, Iwatsubo T, Jellinger KA, Jicha GA, Kövari E, Kukull WA, Leverenz JB, Love S, Mackenzie IR, Mann DM, Masliah E, McKee AC, Montine TJ, Morris JC, Schneider JA, Sonnen JA, Thal DR, Trojanowski JQ, Troncoso JC, Wisniewski T, Woltjer RL, Beach TG. Correlation of Alzheimer disease neuropathologic changes with cognitive status: a review of the literature. $\mathrm{J}$ Neuropathol Exp Neurol. 2012; 71:362-81.

2. Prohovnik I, Perl DP, Davis KL, Libow L, Lesser G, Haroutunian V. Dissociation of neuropathology from severity of dementia in late-onset Alzheimer disease. Neurology. 2006 10; 66:49-55.

3. Holtzman DM, Morris JC, Goate AM. Alzheimer's disease: the challenge of the second century. Sci Transl Med. 2013; $77 \mathrm{sr} 1$.

4. Ballard C, Gauthier S, Corbett A, Brayne C, Aarsland D, Jones E. Alzheimer's disease. Lancet. 2011; 377:1019-31

5. Castellani RJ, Zhu X, Lee HG, Smith MA, Perry G. Molecular pathogenesis of Alzheimer's disease: reductionist versus expansionist approaches. Int J Mol Sci. 2009; 10:1386-406.

6. Bancher C, Jellinger K, Lassmann H, Fischer P, Leblhuber F. Correlations between mental state and quantitative neuropathology in the Vienna longitudinal study on dementia. Eur Arch Psychiatry Clin Neurosci. 1996; 246:137-146.

7. Cummings BJ, Pike CJ, Shankle R, Cotman CW. Betaamyloid deposition and other measures of neuropathology predict cognitive status in Alzheimer's disease. Neurobiol Aging. 1996; 17:921-933.

8. Berg L, McKeel DW,Jr, Miller JP, et al. Clinicopathologic studies in cognitively healthy aging and Alzheimer's disease: Relation of histologic markers to dementia severity, age, sex, and apolipoprotein E genotype. Arch Neurol. 1998; 55:326-335

9. Haroutunian V, Purohit DP, Perl DP, et al. Neurofibrillary tangles in nondemented elderly subjects and mild Alzheimer 
disease. Arch Neurol. 1999; 56:713-718.

10. Guillozet AL, Weintraub S, Mash DC, Mesulam MM. Neurofibrillary tangles, amyloid, and memory in aging and mild cognitive impairment. Arch Neurol. 2003; 60:729-736.

11. Morris GP, Clark IA, Vissel B. Inconsistencies and controversies surrounding the amyloid hypothesis of Alzheimer's disease. Acta Neuropathol Commun. 2014; 2:135.

12. Lesné SE, Sherman MA, Grant M, Kuskowski M, Schneider JA, Bennett DA, Ashe KH. Brain amyloid- $\beta$ oligomers in ageing and Alzheimer's disease. Brain. 2013; 136:1383-98.

13. Bennett DA, Wilson RS, Boyle PA, Buchman AS, Schneider JA. Relation of neuropathology to cognition in persons without cognitive impairment. Ann Neurol. 2012; 72:599-609.

14. Negash S, Wilson RS, Leurgans SE, Wolk DA, Schneider JA, Buchman AS, Bennett DA, Arnold SE. Resilient brain aging: characterization of discordance between Alzheimer's disease pathology and cognition. Curr Alzheimer Res. 2013; 10:844-51.

15. Lue LF, Brachova L, Civin WH, Rogers J. Inflammation, A beta deposition, and neurofibrillary tangle formation as correlates of Alzheimer's disease neurodegeneration. J Neuropathol Exp Neurol. 1996; 55:1083-8.

16. Mochizuki A, Peterson JW, Mufson EJ, Trapp BD. Amyloid load and neural elements in Alzheimer's disease and nondemented individuals with high amyloid plaque density. Exp Neurol. 1996; 142:89-102.

17. Price JL, Morris JC. Tangles and plaques in nondemented aging and "preclinical" Alzheimer's disease. Ann Neurol. 1999; 45:358-68.

18. Aizenstein HJ, Nebes RD, Saxton JA, Price JC, Mathis CA, Tsopelas ND, Ziolko SK, James JA, Snitz BE, Houck PR, Bi W, Cohen AD, Lopresti BJ, DeKosky ST, Halligan EM, Klunk WE. Frequent amyloid deposition without significant cognitive impairment among the elderly. Arch Neurol. 2008; 65:1509-17.

19. Mormino EC, Brandel MG, Madison CM, Rabinovici GD, Marks S, Baker SL, Jagust WJ. Not quite PIB-positive, not quite PIB-negative: slight PIB elevations in elderly normal control subjects are biologically relevant. Neuroimage. 2012; 59:1152-60.

20. Murray J, Tsui WH, Li Y, McHugh P, Williams S, Cummings M, Pirraglia E, Solnes L, Osorio R, Glodzik L, Vallabhajosula S, Drzezga A, Minoshima S, de Leon MJ, Mosconi L1. FDG and Amyloid PET in Cognitively Normal Individuals at Risk for Late-Onset Alzheimer's Disease. Adv J Mol Imaging. 2014; 4:15-26.

21. Whitwell JL, Tosakulwong N, Weigand SD, Senjem ML, Lowe VJ, Gunter JL, Boeve BF, Knopman DS, Dickerson BC, Petersen RC, Jack CR Jr. Does amyloid deposition produce a specific atrophic signature in cognitively normal subjects? Neuroimage Clin. 2013; 2:249-57.

22. Mathis CA, Kuller LH, Klunk WE, Snitz BE, Price JC,
Weissfeld LA, Rosario BL, Lopresti BJ, Saxton JA, Aizenstein HJ, McDade EM, Kamboh MI, DeKosky ST, Lopez OL. In vivo assessment of amyloid- $\beta$ deposition in nondemented very elderly subjects. Ann Neurol. 2013; 73:751-61.

23. Wirth M, Madison CM, Rabinovici GD, Oh H, Landau SM, Jagust WJ. Alzheimer's disease neurodegenerative biomarkers are associated with decreased cognitive function but not $\beta$-amyloid in cognitively normal older individuals. J Neurosci. 2013; 33:5553-63.

24. Driscoll I, Resnick SM, Troncoso JC, An Y, O'Brien R, Zonderman AB. Impact of Alzheimer's pathology on cognitive trajectories in nondemented elderly. Ann Neurol. 2006; 60:688-695.

25. Fouquet M, Besson FL, Gonneaud J, La Joie R, Chételat G. Imaging brain effects of APOE4 in cognitively normal individuals across the lifespan. Neuropsychol Rev. 2014; 24:290-9.

26. Tomlinson BE, Blessed G, Roth M. Observations on the brains of non-demented old people. J Neurol Sci. 1968; 7:331-356.

27. Katzman R, Terry R, DeTeresa R, et al. Clinical, pathological, and neurochemical changes in dementia: A subgroup with preserved mental status and numerous neocortical plaques. Ann Neurol. 1988; 23:138-144.

28. Crystal H, Dickson D, Fuld P, et al. Clinico-pathologic studies in dementia: Nondemented subjects with pathologically confirmed Alzheimer's disease. Neurology. 1988; 38:1682-1687.

29. Troncoso JC, Martin LJ, Dal Forno G, Kawas CH. Neuropathology in controls and demented subjects from the Baltimore longitudinal study of aging. Neurobiol Aging. 1996; 17:365-371.

30. Hulette CM, Welsh-Bohmer KA, Murray MG, Saunders AM, Mash DC, McIntyre LM. Neuropathological and neuropsychological changes in "normal" aging: Evidence for preclinical Alzheimer disease in cognitively normal individuals. J Neuropathol Exp Neurol. 1998; 57:11681174.

31. Knopman DS, Parisi JE, Salviati A, et al. Neuropathology of cognitively normal elderly. J Neuropathol Exp Neurol. 2003; 62:1087-1095.

32. Hyman BT, Phelps CH, Beach TG, Bigio EH, Cairns NJ, Carrillo MC, Dickson DW, Duyckaerts C, Frosch MP, Masliah E, Mirra SS, Nelson PT, Schneider JA, Thal DR, Thies B, Trojanowski JQ, Vinters HV, Montine TJ. National Institute on Aging-Alzheimer's Association guidelines for the neuropathologic assessment of Alzheimer's disease. Alzheimers Dement. 2012; 8:1-13.

33. Montine TJ, Phelps CH, Beach TG, Bigio EH, Cairns NJ, Dickson DW, Duyckaerts C, Frosch MP, Masliah E, Mirra SS, Nelson PT, Schneider JA, Thal DR, Trojanowski JQ, Vinters HV, Hyman BT; National Institute on Aging; Alzheimer's Association. National Institute on Aging- 
Alzheimer's Association guidelines for the neuropathologic assessment of Alzheimer's disease: a practical approach. Acta Neuropathol. 2012; 123:1-11.

34. Riudavets MA, Iacono D, Resnick SM, et al. Resistance to Alzheimer's pathology is associated with nuclear hypertrophy in neurons. Neurobiol Aging. 2007; 28:14841492.

35. Iacono $\mathrm{D}$, O'Brien $\mathrm{R}$, Resnick $\mathrm{SM}$, Zonderman $\mathrm{AB}$, Pletnikova O, Rudow G, An Y, West MJ, Crain B, Troncoso JC. Neuronal hypertrophy in asymptomatic Alzheimer disease. J Neuropathol Exp Neurol. 2008; 67:578-89.

36. Iacono D, O'Brien R, Resnick SM, et al. Neuronal hypertrophy in asymptomatic Alzheimer disease. J Neuropathol Exp Neurol. 2008; 67:578-589.

37. Iacono D, Markesbery WR, Gross M, Pletnikova O, Rudow G, Zandi P, Troncoso JC. The Nun Study: clinically silent $\mathrm{AD}$, neuronal hypertrophy, and linguistic skills in early life. Neurology. 2009; 73:665-73.

38. Clément F, Gauthier S, Belleville S. Executive functions in mild cognitive impairment: emergence and breakdown of neural plasticity. Cortex. 2013; 49:1268-79.

39. Cohen AD, Price JC, Weissfeld LA, James J, Rosario BL, Bi W, Nebes RD, Saxton JA, Snitz BE, Aizenstein HA, Wolk DA, Dekosky ST, Mathis CA, Klunk WE. Basal cerebral metabolism may modulate the cognitive effects of Abeta in mild cognitive impairment: an example of brain reserve. J Neurosci. 2009; 29:14770-8.

40. Ashraf A, Fan Z, Brooks DJ, Edison P. Cortical hypermetabolism in MCI subjects: a compensatory mechanism? Eur J Nucl Med Mol Imaging. 2015; 42:44758.

41. Förster S, Yousefi BH, Wester HJ, Klupp E, Rominger A, Förstl H, Kurz A, Grimmer T, Drzezga A. Quantitative longitudinal interrelationships between brain metabolism and amyloid deposition during a 2-year follow-up in patients with early Alzheimer's disease. Eur J Nucl Med Mol Imaging. 2012; 39:1927-36.

42. Iacono D, Resnick SM, O'Brien R, Zonderman AB, An Y, Pletnikova O, Rudow G, Crain B, Troncoso JC. Mild cognitive impairment and asymptomatic Alzheimer disease subjects: equivalent $\beta$-amyloid and tau loads with divergent cognitive outcomes. J Neuropathol Exp Neurol. 2014; 73:295-304.

43. Snowdon DA. Aging and Alzheimer's disease: lessons from the Nun Study. Gerontologist. 1997; 37:150-6.

44. Snowdon DA. Healthy aging and dementia: findings from the Nun Study. Ann Intern Med. 2003; 139:450-4.

45. Seripa D, D’Onofrio G, Panza F, Cascavilla L, Masullo C, Pilotto A. The genetics of the human APOE polymorphism. Rejuvenation Res. 2011; 14:491-500.

46. Corder EH, Saunders AM, Risch NJ, et al. Protective effect of apolipoprotein E type 2 allele for late onset Alzheimer disease. Nat Genet. 1994; 7:180-184.

47. Brayne C, Ince PG, Keage HA, McKeith IG, Matthews FE,
Polvikoski T, Sulkava R, EClipSE Collaborative Members. Education, the brain and dementia: neuroprotection or compensation? Brain. 2010; 133:2210-6.

48. Snowdon DA, Kemper SJ, Mortimer JA, Greiner LH, Wekstein DR, Markesbery WR. Linguistic ability in early life and cognitive function and Alzheimer's disease in late life. Findings from the Nun Study.JAMA. 1996; 275:52832.

49. Snowdon DA, Greiner LH, Markesbery WR. Linguistic ability in early life and the neuropathology of Alzheimer's disease and cerebrovascular disease. Findings from the Nun Study.Ann N Y Acad Sci. 2000; 903:34-8.

50. Riley KP, Snowdon DA, Markesbery WR. Alzheimer's neurofibrillary pathology and the spectrum of cognitive function: Findings from the nun study. Ann Neurol. 2002; 51:567-577.

51. Morris JC, Heyman A, Mohs RC, et al. The consortium to establish a registry for Alzheimer's disease (CERAD). Part I. clinical and neuropsychological assessment of Alzheimer's disease. Neurology. 1989; 39:1159-1165.

52. Welsh KA, Butters N, Mohs RC, et al. The consortium to establish a registry for Alzheimer's disease (CERAD). Part V. A normative study of the neuropsychological battery. Neurology. 1994; 44:609-614.

53. Petersen RC, Smith GE, Waring SC, Ivnik RJ, Tangalos EG, Kokmen E. Mild cognitive impairment: clinical characterization and outcome. Arch Neurol. 1999; 56:3038.

54. Albert MS, DeKosky ST, Dickson D, Dubois B, Feldman HH, Fox NC, Gamst A, Holtzman DM, Jagust WJ, Petersen RC, Snyder PJ, Carrillo MC, Thies B, Phelps CH. The diagnosis of mild cognitive impairment due to Alzheimer's disease: recommendations from the National Institute on Aging-Alzheimer's Association workgroups on diagnostic guidelines for Alzheimer's disease. Alzheimers Dement. 2011; 7:270-9.

55. Mirra SS, Heyman A, McKeel D, et al. The consortium to establish a registry for Alzheimer's disease (CERAD). Part II. Standardization of the neuropathologic assessment of Alzheimer's disease. Neurology. 1991; 41:479-486.

56. Braak H, Braak E. Neuropathological stageing of Alzheimer-related changes. Acta Neuropathol (Berl). 1991; 82:239-259.

57. Hyman BT, Trojanowski JQ. Consensus recommendations for the postmortem diagnosis of Alzheimer disease from the National Institute on Aging and the Reagan Institute Working Group on diagnostic criteria for the neuropathological assessment of Alzheimer disease. J Neuropathol Exp Neurol. 1997; 56:1095-7.

58. Hyman BT, Phelps CH, Beach TG, Bigio EH, Cairns NJ, Carrillo MC, Dickson DW, Duyckaerts C, Frosch MP, Masliah E, Mirra SS, Nelson PT, Schneider JA, Thal DR, Thies B, Trojanowski JQ, Vinters HV, Montine TJ. National Institute on Aging-Alzheimer's Association guidelines for 
the neuropathologic assessment of Alzheimer's disease. Alzheimers Dement. 2012; 8:1-13.

59. Hixson JE, Vernier DT. Restriction isotyping of human apolipoprotein $\mathrm{E}$ by gene amplification and cleavage with HhaI. J Lipid Res. 1990; 31:545-548.

60. Talbot C, Lendon C, Craddock N, Shears S, Morris JC, Goate A. Protection against Alzheimer's disease with ApoE epsilon 2. Lancet. 1994; 343:1432-1433.

61. Bennett DA, Wilson RS, Schneider JA, Evans DA, Mendes de Leon CF, Arnold SE, et al. Education modifies the relation of $\mathrm{AD}$ pathology to level of cognitive function in older persons. Neurology 2003; 60:1909-15.

62. Pettigrew C, Soldan A, Li S, Lu Y, Wang MC, Selnes OA, Moghekar A, O’Brien R, Albert M, The Biocard Research Team. Relationship of cognitive reserve and APOE status to the emergence of clinical symptoms in preclinical Alzheimer's disease. Cogn Neurosci. 2013; 4:136-42.

63. Wilson RS, Bienias JL, Berry-Kravis E, Evans DA, Bennett DA. The apolipoprotein E epsilon 2 allele and decline in episodic memory. J Neurol Neurosurg Psychiatry. 2002; 73:672-7.

64. Conejero-Goldberg C, Gomar JJ, Bobes-Bascaran T, Hyde TM, Kleinman JE, Herman MM, Chen S, Davies $\mathrm{P}$, Goldberg TE. APOE2 enhances neuroprotection against Alzheimer's disease through multiple molecular mechanisms. Mol Psychiatry. 2014; 19:1243-50.

65. Serrano-Pozo A, Qian J, Monsell SE, Betensky RA, Hyman BT. APOE\&2 is associated with milder clinical and pathological Alzheimer's disease. Ann Neurol. 2015; 77: 917-29.

66. Poirier J. Apolipoprotein E in animal models of CNS injury and in Alzheimer's disease. Trends Neurosci. 1994; 17:525530.

67. Levi O, Jongen-Relo AL, Feldon J, Roses AD, Michaelson DM. ApoE4 impairs hippocampal plasticity isoformspecifically and blocks the environmental stimulation of synaptogenesis and memory. Neurobiol Dis. 2003; 13:273282.

68. Ji Y, Gong Y, Gan W, Beach T, Holtzman DM, Wisniewski T. Apolipoprotein E isoform-specific regulation of dendritic spine morphology in apolipoprotein E transgenic mice and Alzheimer's disease patients. Neuroscience. 2003; 122:305315.

69. Petit-Turcotte C, Aumont N, Beffert U, Dea D, Herz J, Poirier J. The apoE receptor apoER2 is involved in the maintenance of efficient synaptic plasticity. Neurobiol Aging. 2005; 26:195-206.

70. Lippa CF, Smith TW, Saunders AM, Hulette C, PulaskiSalo D, Roses AD. Apolipoprotein E-epsilon 2 and Alzheimer's disease: genotype influences pathologic phenotype. Neurology. 1997; 48:515-9.

71. Tindale LC, Leach S, Ushey K, Daley D, Brooks-Wilson AR. Rare and common variants in the Apolipoprotein E gene in healthy oldest old. Neurobiol Aging. 2014; 35:727. e1-3.

72. Schächter F, Faure-Delanef L, Guénot F, Rouger H, Froguel P, Lesueur-Ginot L, Cohen D. Genetic associations with human longevity at the APOE and ACE loci. Nat Genet. 1994; 6:29-32.

73. Christensen K, Johnson TE, Vaupel JW. The quest for genetic determinants of human longevity: challenges and insights. Nat Rev Genet. 2006; 7:436-48.

74. Broer L, Buchman AS, Deelen J, Evans DS, Faul JD, Lunetta KL, Sebastiani P, Smith JA, Smith AV, Tanaka T, Yu L, Arnold AM, Aspelund T, Benjamin EJ, De Jager PL, Eirkisdottir G, Evans DA, Garcia ME, Hofman A, Kaplan RC, Kardia SL, Kiel DP, Oostra BA, Orwoll ES, Parimi N, Psaty BM, Rivadeneira F, Rotter JI, Seshadri S, Singleton A, Tiemeier H, Uitterlinden AG, Zhao W, Bandinelli S, Bennett DA, Ferrucci L, Gudnason V, Harris TB, Karasik D, Launer LJ, Perls TT, Slagboom PE, Tranah GJ, Weir DR, Newman AB, van Duijn CM, Murabito JM. GWAS of Longevity in CHARGE Consortium Confirms APOE and FOXO3 Candidacy. J Gerontol A Biol Sci Med Sci. 2015; 70:110-8.

75. Grammer TB, Hoffmann MM, Scharnagl H, Kleber ME, Silbernagel G, Pilz S, Tomaschitz A, Lerchbaum E, Siekmeier R, März W. Smoking, apolipoprotein E genotypes, and mortality (the Ludwigshafen RIsk and Cardiovascular Health study). Eur Heart J. 2013; 34:1298305.

76. Gale SC, Gao L, Mikacenic C, Coyle SM, Rafaels N, Murray Dudenkov T, Madenspacher JH, Draper DW, Ge W, Aloor JJ, Azzam KM, Lai L, Blackshear PJ, Calvano SE, Barnes KC, Lowry SF, Corbett S, Wurfel MM, Fessler $\mathrm{MB}$. APO 4 is associated with enhanced in vivo innate immune responses in human subjects. J Allergy Clin Immunol. 2014; 134:127-34.

77. Beach TG, Monsell SE, Phillips LE, Kukull W. Accuracy of the clinical diagnosis of Alzheimer disease at National Institute on Aging Alzheimer Disease Centers, 2005-2010. J. Neuropathol. Exp. Neurol. 2012; 71:266-273.

78. Stern Y. Cognitive reserve and Alzheimer disease. Alzheimer Dis Assoc Disord. 2006; 20:112-117

79. Iacono D, Volkman I, Nennesmo I, Pedersen NL, Fratiglioni L, Johansson B, Karlsson D, Winblad B, Gatz M. Neuropathologic assessment of dementia markers in identical and fraternal twins. Brain Pathol. 2014; 24:317-33. 